measurements were significant predictors for the development of POAF. However, when applied in multivariable models, none of the strain measurements gained significance. Yet, there was a large increase in the $C$-statistic going from a model that did not include any strain measurements to those that did; clearly the strain information is improving prediction. A reason behind this discrepancy could be that all the strain measurements are not in isolation from one another. Through complex biomechanics, 1 strain measurement gives rise to another. This explains why they were all individually significant on univariable analysis but not on multivariable analysis. This is further underscored by all the strain values being statistically different between the cohorts. Promisingly, the smallest change in the $C$-statistic going from univariable to the cross-validated multivariable occurs with the LA pump strain and LA peak reservoir strain. This suggests that in this study, these 2 strain values influenced the model the best and should be examined in isolation on further research.

These authors put forth a compelling article that exemplifies the benefits of applying biomechanics to cardiac surgery outcomes. The next breakthrough in cardiac surgery will be routine and established utilization of cardiac biomechanics in all aspects of patient care and this article is an important piece of that journey.

\section{References}

1. Smiseth OA, Torp H, Opdahl A, Haugaa KH, Urheim S. Myocardial strain imaging: how useful is it in clinical decision making? Eur Heart J. 2016;37: 1196-207.

2. Kislitsina JLC, Shah SJ, Malaisrie C, Kruse J, Liu M, Andrei A-C, et al. Preoperative left atrial strain abnormalities are associated with the development of postoperative atrial fibrillation following isolated coronary artery bypass surgery. $J$ Thorac Cardiovasc Surg. 2022;164:917-24.

3. Mulukutla SR, Gleason TG, Sharbaugh M, Sultan I, Marroquin OC, Thoma F, et al. Coronary bypass versus percutaneous revascularization in multivessel coronary artery disease. Ann Thorac Surg. 2019;108:474-80.

4. Bianco V, Kilic A, Gleason TG, Aranda-Michel E, Wang Y, Navid F, et al. Timing of coronary artery bypass grafting after acute myocardial infarction may not influence mortality and readmissions. J Thorac Cardiovasc Surg. 2021;161: 2056-64.e4.

5. Augustin CM, Fastl TE, Neic A, Bellini C, Whitaker J, Rajani R, et al. The impact of wall thickness and curvature on wall stress in patient-specific electromechanical models of the left atrium. Biomech Model Mechanobiol. 2020;19:1015-34.

6. Krishnamurthy A, Villongco CT, Chuang J, Frank LR, Nigam V, Belezzuoli E, et al. Patient-specific models of cardiac biomechanics. J Comput Phys. 2013; 244:4-21.

\title{
Commentary: POAF goes POOF!
}

\begin{abstract}
Alden H. Harken, MD
Until recently, most of us appreciated postoperative atrial fibrillation (POAF), especially in routine, otherwise healthy patients undergoing coronary artery bypass grafting (CABG), as an irritating but otherwise insignificant stumble. We recognize that POAF has the most common complications associated with cardiac surgery, but it was pretty easy to treat and we could convince our patients and their families that POAF was no big deal. Then, several huge studies-involving almost 10,000 patients-identified an approximately $50 \%$ increase in mortality associated with
\end{abstract}

From the University of California San Francisco-East Bay (retired), Alamo, Calif. Disclosures: The author reported no conflicts of interest.

The Journal policy requires editors and reviewers to disclose conflicts of interest and to decline handling or reviewing manuscripts for which they may have a conflict of interest. The editors and reviewers of this article have no conflicts of interest.

Received for publication Oct 1, 2020; revisions received Oct 1, 2020; accepted for publication Oct 1, 2020; available ahead of print Oct 9, 2020.

Address for reprints: Alden H. Harken, MD, 1565 Alamo Way, Alamo, CA 94595 (E-mail: alden.harken68@gmail.com).

J Thorac Cardiovasc Surg 2022;164:926-7 $0022-5223 / \$ 36.00$

Copyright $₫ 2020$ Published by Elsevier Inc. on behalf of The American Association for Thoracic Surgery

https://doi.org/10.1016/j.jtcvs.2020.10.005

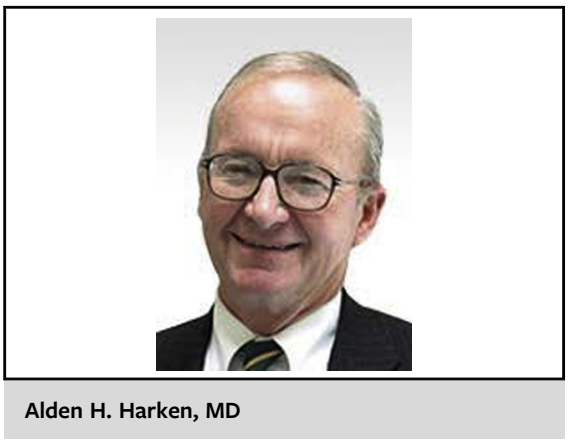

CENTRAL MESSAGE

Incorporating calculated left atrial strain into a patient's perioperative rhythm prophylaxis program might preclude nontherapeutic antidysrhythmic therapy.

POAF. That is a $50 \%$ increase in a gratifyingly small elective CABG mortality, but POAF was also linked to an increase in length of patient stay and hospital cost. This irritant caught our attention. We were successful in 
dramatically reducing POAF by simply blasting all elective CABG patients with temporary perioperative antidysrhythmic agents. Never more than one-third of untreated patients ever experienced POAF, so we have been slamming the other two-thirds of patients with nontherapeutic therapies. The goal of the authors ${ }^{1}$ was to identify some parameter that might distinguish the one-third of patients who would actually benefit from prophylaxis to save the other twothirds from useless prophylaxis.

Most of us believe that atrial hypertension causes the atrial muscle to stretch, which can result in microischemia and we all know that ischemia results in hyperexcitability. We've got a mechanism.

The authors performed transthoracic echocardiograms on 211 elective CABG patients and then calculated both the left atrial volume index and preoperative left atrial strain by speckle tracking analysis. Both older age and calculated left atrial compliance were associated with POAF.

The authors have achieved the investigative Holy Grail: A hypothesis driven, mechanistically based, and clinically relevant study. All we need to know now is whether speckle analysis is more or less time and more or less financially expensive than a couple doses of propranolol.

\section{Reference}

1. Kislitsina ON, Cox JL, Shah SJ, Malaisrie SC, Kruse J, Liu M, et al. Preoperative left atrial strain abnormalities are associated with the development of postoperative atrial fibrillation following isolated coronary artery bypass surgery. $J$ Thorac Cardiovasc Surg. 2022;164:917-24. 